\title{
Lack of effect of high doses of inhaled morphine on exer- cise endurance in chronic obstructive pulmonary disease
}

\author{
D. Jankelson*, K. Hosseini*, L.E. Mather**, J.P. Seale+, I.H. Young*
}

Lack of effect of high doses of inhaled morphine on exercise endurance in chronic obstructive pulmonary disease. D. Jankelson, K. Hosseini, L.E. Mather, J.P. Seale, I.H. Young. (CERS Journals Ltd 1997.

ABSTRACT: Systemic opiates may relieve dyspnoea and improve exercise tolerance in patients with chronic obstructive pulmonary disease (COPD). Small doses of inhaled opiates may have similar effects; however, recent studies have shown no benefit. We studied higher doses of inhaled morphine and measured systemic absorption to determine whether any beneficial actions are local or systemic.

Twenty and $40 \mathrm{mg}$ doses and $0.9 \%$ saline were nebulized in a randomized, double-blind study of 16 patients with stable COPD. Patients performed 6 min walk tests immediately after the nebulized test solution (Walk 1) and again 60 min later (Walk 2). Arterial oxygen saturation $\left(\mathrm{S}_{\mathrm{a}}, \mathrm{O}_{2}\right)$, modified Borg dyspnoea score and cardiac frequency were recorded during each walk.

There was no difference between placebo and either dose of nebulized morphine on these measurements. The higher dose of nebulized morphine achieved a higher plasma concentration. The highest plasma concentration was measured immediately after nebulization, and this decreased steadily in the hour thereafter $(p<0.002)$. There was no correlation between the change in walk distance and the change in plasma morphine concentration after either dose of nebulized morphine.

We conclude that higher doses of nebulized morphine do not improve exercise endurance or relieve dyspnoea in patients with chronic obstructive pulmonary disease, and that morphine is rapidly absorbed systemically after inhalation. Eur Respir J 1997; 10: 2270-2274.
Depts of * Respiratory Medicine and ${ }^{+}$Clinical Pharmacology, Royal Prince Alfred Hospital, Camperdown, NSW, Australia. **Dept of Anaesthetics, Royal North Shore Hospital, Sydney, Australia.

Correspondence: I.H. Young

Dept of Respiratory Medicine

Royal Prince Alfred Hospital

Missenden Road

Camperdown

NSW 2050

Australia

Keywords: Chronic obstructive pulmonary disease

dyspnoea

exercise endurance

nebulized morphine

Received: January 271997

Accepted after revision July 71997
Chronic obstructive pulmonary disease (COPD) is a common respiratory disorder for which treatment options are limited. Dyspnoea is a troublesome symptom of COPD, which consistently limits quality of life [1]. Amongst the diverse approaches for relieving dyspnoea, the use of medications such as dihydrocodeine [2] and diazepam [3] have been assessed as having limited success. The use of oral morphine resulted in a $20 \%$ increase in exercise capacity in one study but unwanted side-effects, such as nausea, mental cloudiness and hypotension, may occur [4]. More recently, inhaled morphine has been evaluated in COPD, on the assumption (from animal experimental data) that there may be intrapulmonary opioid receptors [5] that would be more readily accessed by the inhaled route of drug delivery, thereby avoiding systemic side-effects.

Studies using progressive cycle-ergometer exercise to induce dyspnoea have tested doses ranging 1-25 mg, and have indicated no clinically significant benefit of morphine on exercise endurance or on the sensation of dyspnoea [6-8]. However, it is probable that the 6 min walk test is a more clinically relevant tool for assessing the potential value of therapeutic interventions in patients with COPD [9]. In a previous study, we reported that a small dose of inhaled morphine $(5 \mathrm{mg}$ deliv- ered, calculated as about $1 \mathrm{mg}$ deposited in the lung) increased the exercise endurance in a small group of patients with chronic lung disease [10]. Most patients had advanced COPD, and a significant benefit for exercise endurance on a bicycle at a steady workload was demonstrated. However, these results were weighted by two patients who showed a very substantial improvement, and other changes were modest.

Subsequent studies using a variety of assessment procedures showed no benefit $[6-8,11,12]$, with the exception of a study reporting a significant benefit from inhaled morphine-6-glucuronide during endurance cycle exercise [12]. In view of these discrepant findings, the present study was carried out in patients with COPD to determine: 1) if higher doses of inhaled morphine than have been previously used can improve exercise endurance and dyspnoea; and 2) if there is significant systemic absorption of inhaled morphine at these higher doses. In this way, we aimed to differentiate whether any beneficial actions of inhaled morphine are local or systemic. Also, the timing of the two 6 min walk tests immediately after nebulization and $1 \mathrm{~h}$ later was designed to test the hypothesis that an immediate improvement in exercise endurance, before plasma levels were detected, would have indicated a local effect. 


\section{Materials and methods}

\section{Patient selection}

Sixteen patients with COPD, attending the Royal Prince Alfred Hospital participated in the study. Eligibility criteria included: 1) exercise limited by dyspnoea; 2) forced expiratory volume in one second (FEV1) less than $50 \%$ predicted; 3 ) a resting arterial carbon dioxide tension $\left(\mathrm{Pa}, \mathrm{CO}_{2}\right)$ less than $8.0 \mathrm{kPa}(60 \mathrm{mmHg})$; and 4) no recent acute exacerbation of COPD. Patients were excluded if there was: 1) a history or clinical evidence of haemodynamically significant cardiac disease causing dyspnoea; 2) significant arthritis or other musculoskeletal disorders causing pain on walking; 3) significant disease affecting major organ systems, such as renal failure, liver failure or neuromuscular disease affecting exercise performance; and 4) ingestion of opioids or opioid medications within 1 month of the study, major tranquillizers within 1 week, and benzodiazepines less than $24 \mathrm{~h}$ prior to the study. The protocol was approved by the Royal Prince Alfred Hospital Ethics Committee and informed consent was obtained from each patient.

\section{Protocol}

On a screening day, each patient was assessed clinically to ensure that he or she met the entry criteria. Baseline investigations, including arterial blood gas values and spirometry (FEV1 and forced vital capacity (FVC)), were obtained. A 6 min walk test (see below) was performed twice to familiarize the patient with the procedure and to assess baseline exercise endurance. A double-blind cross-over, placebo-controlled design was followed. Three test solutions, morphine sulphate (20 and $40 \mathrm{mg}$ in $5 \mathrm{~mL}$ solutions with $0.9 \%$ saline) and placebo ( $5 \mathrm{~mL} 0.9 \%$ saline), were prepared and allocated by the hospital pharmacist in a double-blind, random order on each of three test days, which were no more than 2 days apart. On each test day, patients were instructed to eat a light breakfast and to avoid drinks containing caffeine. They were allowed to take their usual medications. Spirometry was performed and a venous cannula was inserted to obtain blood samples for measurements of the plasma morphine concentration. Patients then inhaled one of the test solutions via a Side Stream jet nebulizer (Trimed Pty Ltd, North Ryde, Sydney, Australia) and mouthpiece, driven by oxygen at a flow rate of $6 \mathrm{~L} \cdot \mathrm{min}^{-1}$, generating aerosol particles with a mass median diameter of $3.0 \mu \mathrm{m}$. This is a smaller particle size than generated by the usual clinical nebulizer and was chosen to maximize deposition in the alveolated lung.

The patient inhaled with tidal breathing for $15 \mathrm{~min}$ while sitting comfortably. After completion of the nebulization, the first 6 min walk test was performed [9]. Each patient walked a measured distance as far as possible in $6 \mathrm{~min}$ (6MWD). The patient could slow down or stop to rest if necessary. Arterial oxygen saturation $\left(\mathrm{S}_{\mathrm{a}} \mathrm{O}_{2}\right)$ and cardiac frequency were monitored, dyspnoea was measured using the modified Borg dyspnoea scale [13], and the results were recorded at 1 min intervals. Criteria for the cessation of the exercise test included: angina, sudden pallor, cyanosis or exhaustion. The pati- ent then rested and 60 min after the completion of the nebulization a second 6 min walk test was performed. Blood samples for morphine concentrations were taken as follows: 1) before nebulization; 2) immediately after completion of the nebulization just before the first 6 min walk test; 3) 30 min after the nebulization; and 4) $60 \mathrm{~min}$ postnebulization just prior to the second 6 min walk test. Plasma was separated immediately by centrifugation and samples stored at $-80^{\circ} \mathrm{C}$ for subsequent analysis of morphine concentrations.

\section{Assay of morphine concentration}

Plasma morphine concentrations were determined by solvent extraction followed by gas chromatography-mass spectrometry using selected ion monitoring with nalorphine as the internal standard. Sample preparation involved: extraction of basified plasma samples at $\mathrm{pH} 9.0$ using $n$-butyl chloride:chloroform (5:1); concentration of the extracts to dryness; and derivatization of the residues with pentafluoropropionic anhydride. The derivatives were concentrated to dryness, reconstituted in toluene and injected onto the chromatograph. For a plasma sample size of $1 \mathrm{~mL}$, the limit of quantification was $1 \mathrm{ng} \cdot \mathrm{mL}^{-1}$ (signal to noise $(\mathrm{S} / \mathrm{N})$ ratio $10: 1$ ); the estimated limit of detection was calculated to be $0.3 \mathrm{ng} \cdot \mathrm{mL}^{-1}$ ( $\mathrm{S} / \mathrm{N}$ ratio 3:1) expressed as morphine sulphate pentahydrate, i.e. dose equivalents. Standard curves for the ranges $0-200,0-500$ and $0-1,000 \mathrm{ng} \cdot \mathrm{mL}^{-1}$ morphine in plasma were linear with all $\mathrm{r}^{2}$ values greater than 0.99 .

\section{Statistical analysis}

Comparisons were made between treatments using repeated measures analysis of variance (ANOVA). Post hoc analysis was performed using Duncan's test. A pvalue of less than 0.05 was considered significant. Pearson correlation coefficients were used to assess the relationship between changes in 6MWD and changes in morphine concentration.

\section{Results}

The patients' characteristics are presented in table 1 . The mean age of the group was 69 yrs (range 61-85 yrs). All patients were exsmokers with marked airways obstruction. The mean FEV1 and FVC for the group were 0.93 and $2.21 \mathrm{~L}$, respectively. Gas exchange was moderately impaired in most patients with a mean arterial oxygen tension $\left(\mathrm{Pa}, \mathrm{O}_{2}\right) 9.6 \mathrm{kPa}(72 \mathrm{mmHg})$ and $\mathrm{Pa}_{\mathrm{a}} \mathrm{CO}_{2}$ $5.4 \mathrm{kPa}(41 \mathrm{mmHg})$ for the group; however, three patients (Nos. 5, 9 and 14) were in more advanced respratory failure with one being on continuous oxygen supplementation. Two patients had previous cerebrovascular accidents but the residual neurological impairment did not affect their exercise performance. Two patients had pleural thickening from previous empyaemas (Nos. 13 and 15). There were no significant changes in FEV1 and FVC between baseline and test days in all subjects.

The $40 \mathrm{mg}$ dose of nebulized morphine achieved a higher plasma concentration than the $20 \mathrm{mg}$ dose (fig. 1 ). For both doses of nebulized morphine, the highest 
Table 1. - Characteristics of the patients studied

\begin{tabular}{cccccccc}
\hline $\begin{array}{l}\text { Pt } \\
\text { No. }\end{array}$ & $\begin{array}{l}\text { Age } \\
\text { yrs }\end{array}$ & Sex & $\begin{array}{c}\text { Smoking } \\
\text { pack-yrs }\end{array}$ & $\begin{array}{c}\mathrm{FEV} 1 \\
\mathrm{~L}\end{array}$ & $\begin{array}{c}\mathrm{FVC} \\
\mathrm{L}\end{array}$ & $\begin{array}{c}\mathrm{Pa}_{\mathrm{a}} \mathrm{O}_{2} \\
\mathrm{kPa}\end{array}$ & $\begin{array}{c}\mathrm{Pa}_{\mathrm{a}, \mathrm{CO}_{2}} \\
\mathrm{kPa}\end{array}$ \\
\hline 1 & 77 & $\mathrm{M}$ & $?$ & 0.93 & 2.83 & 8.3 & 5.2 \\
2 & 69 & $\mathrm{M}$ & 50 & 0.55 & 1.67 & 8.8 & 4.4 \\
3 & 71 & $\mathrm{~F}$ & 30 & 0.68 & 2.00 & 8.4 & 5.2 \\
4 & 85 & $\mathrm{M}$ & 40 & 1.39 & 3.30 & 8.9 & 4.5 \\
5 & 64 & $\mathrm{M}$ & 40 & 0.40 & 1.20 & 7.1 & 6.3 \\
6 & 74 & $\mathrm{~F}$ & 35 & 1.08 & 2.73 & 11.7 & 5.3 \\
7 & 81 & $\mathrm{~F}$ & 65 & 0.80 & 1.60 & 10.3 & 5.7 \\
8 & 70 & $\mathrm{M}$ & $?$ & 0.64 & 1.84 & 10.7 & 5.6 \\
9 & 62 & $\mathrm{M}$ & 30 & 0.50 & 1.60 & 7.5 & 7.7 \\
10 & 55 & $\mathrm{M}$ & 80 & 1.15 & 3.30 & 10.1 & 5.1 \\
11 & 67 & $\mathrm{M}$ & 30 & 0.85 & 2.50 & 10.7 & 5.1 \\
12 & 64 & $\mathrm{M}$ & 80 & 1.25 & 2.30 & 10.0 & 5.5 \\
13 & 72 & $\mathrm{~F}$ & 5 & 1.15 & 2.10 & 12.4 & 5.1 \\
14 & 61 & $\mathrm{M}$ & 40 & 0.75 & 1.75 & $9.1{ }^{\#}$ & 5.6 \\
15 & 69 & $\mathrm{M}$ & 45 & 1.50 & 2.40 & 10.0 & 4.8 \\
16 & 67 & $\mathrm{~F}$ & 75 & 1.30 & 2.25 & $\mathrm{ND}$ & $\mathrm{ND}$ \\
\hline Mean & 69 & & 46 & 0.93 & 2.21 & 9.6 & 5.4 \\
\hline
\end{tabular}

Pt: patient; FEV1: forced expiratory volume in one second; FVC: forced vital capacity; $P \mathrm{a}, \mathrm{O}_{2}$ : arterial oxygen tension; $P \mathrm{a}, \mathrm{CO}_{2}$ : arterial carbon dioxide tension; M: male; $\mathrm{F}$ : female. ND: not determined; ?: not known; \#: on $2 \mathrm{~L} \cdot \mathrm{min}^{-1}$ oxygen. $1 \mathrm{kPa}=7.5 \mathrm{mmHg}$.

plasma concentration was measurable immediately after nebulization and the plasma concentration decreased steadily in the hour thereafter $(\mathrm{p}<0.002)$, although the rate of decline was not parallel $(\mathrm{p}<0.02)$.

The exercise endurance results did not support either of the initial hypotheses, i.e. that a higher dose of nebulized morphine may improve exercise endurance and

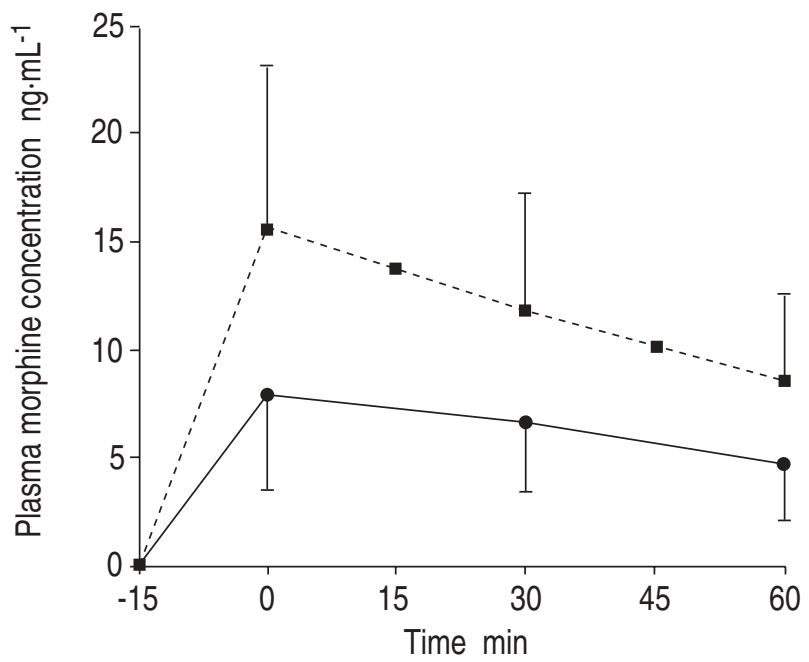

Fig. 1. - Plasma morphine concentrations before (-15), immediately after (0) and at 30 and $60 \mathrm{~min}$ postnebulization. Values are presented as mean \pm SD. $\longrightarrow$ : $20 \mathrm{mg}$ morphine; - 드.-.. $: 40 \mathrm{mg}$ morphine. that an early increase in endurance may indicate a local effect on the lung. All patients described dyspnoea as the limiting symptom after all the 6 min walk tests. One patient (No. 13) experienced light-headedness after the $40 \mathrm{mg}$ dose of nebulized morphine. No side-effects were reported by any of the other patients. There was no difference between placebo and either dose of nebulized morphine on walk distance, $\mathrm{Sa}_{\mathrm{a}} \mathrm{O}_{2}$, dyspnoea or cardiac frequency (table 2 and fig. 2). There was no correlation between the change in $6 \mathrm{MWD}$ and the change in plasma morphine concentration after either dose of nebulized morphine (fig. 2).

\section{Discussion}

In this study, nebulized doses of morphine higher than those previously reported were administered. These doses were chosen because we had previously found some efficacy with a nebulized dose of $5 \mathrm{mg}$ [10], but subsequent studies using doses of 1-25 $\mathrm{mg}$ have not shown benefit $[6-8,11,12]$. Since nebulized doses of

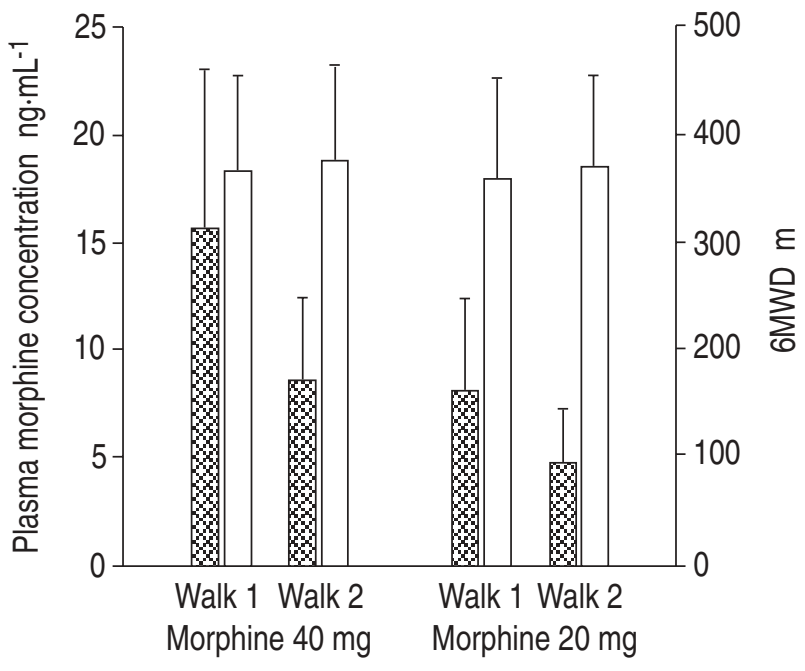

Fig. 2. - Relationship between 6 min walk distance (6MWD) and plasma morphine concentration. Data are presented as mean \pm SD. $\$$ : plasma morphine concentration; $\square$ : 6MWD

Table 2. - Lowest $\mathrm{Sa}, \mathrm{O}_{2}$, highest Borg score and maximum cardiac frequency during tests 1 and 2

\begin{tabular}{lcccr}
\hline & Saline & $\begin{array}{c}\text { Morphine } \\
20 \mathrm{mg}\end{array}$ & $\begin{array}{c}\text { Morphine } \\
40 \mathrm{mg}\end{array}$ & p-value \\
\hline $\mathrm{Sa}_{\mathrm{a}, \mathrm{O}_{2}}$ 1 \% & $86.8 \pm 3.3$ & $86.8 \pm 6.9$ & $87.2 \pm 6.6$ & 0.93 \\
$\mathrm{Sa}_{\mathrm{O}} 2 \%$ & $87.6 \pm 5.8$ & $87.9 \pm 6.2$ & $87.9 \pm 5.8$ & 0.68 \\
$\mathrm{Borg} 1(1-10)$ & $4.3 \pm 2.2$ & $4.2 \pm 2.1$ & $4.3 \pm 1.8$ & 0.88 \\
$\mathrm{Borg} 2(1-10)$ & $4.5 \pm 2.6$ & $3.8 \pm 2.3$ & $4.0 \pm 2.0$ & 0.19 \\
$f \mathrm{C}$ 1 beats $\cdot \mathrm{min}^{-1}$ & $113.9 \pm 12.2$ & $111.9 \pm 12.3$ & $114.1 \pm 12.1$ & 0.76 \\
$f \mathrm{C}$ 2 beats.min & $114.4 \pm 13.5$ & $113.4 \pm 13.9$ & $113.6 \pm 13.3$ & 0.89 \\
\hline
\end{tabular}

Values are presented as mean $\pm \mathrm{SD}$. $\mathrm{Sa}_{\mathrm{a}} \mathrm{O}_{2}$ : arterial oxygen tension; $f \mathrm{C}$ : cardiac frequency. 
$10 \mathrm{mg}$ have been administered without adverse central nervous system effects [11], doses of 20 and $40 \mathrm{mg}$ were chosen to determine the effects of these higher doses on exercise endurance and dyspnoea. Furthermore, a nebulizer that delivers a small particle size (mass median diameter $3 \mu \mathrm{m}$ ) was used to maximize peripheral lung deposition. Compared with saline administration, neither dose of morphine had a significant effect on 6MWD, dyspnoea or $\mathrm{Sa}_{\mathrm{a}} \mathrm{O}_{2}$ either immediately after nebulization or $1 \mathrm{~h}$ later. It was notable that there were no clinically significant side-effects despite the rapid absorption of morphine from the lung, as demonstrated by the plasma concentrations. Although these high nebulized doses are devoid of significant side-effects, we doubt that there is likely to be any useful clinical benefit in testing even higher nebulized doses.

In assessing the potential benefit of inhaled morphine on exercise in patients with COPD, different types of exercise tests have been employed. A consistent finding has been the failure of morphine to have any significant effects on dyspnoea or exercise tolerance when progressive exercise testing has been employed [6-8]. It is noteworthy that the only studies that have reported a positive effect with inhaled opiates in COPD have employed endurance testing $[10,12]$. The 6 min walk test was chosen for this study because we regard it as a clinically relevant test for patients with COPD as it is related to their day-to-day activities. Thus, we believe that it is an appropriate test with which to assess the potential usefulness of drugs for relieving dyspnoea in patients with COPD.

There was significant and rapid systemic absorption of morphine with both nebulized doses. The plasma concentrations of morphine on completion of nebulizing $40 \mathrm{mg}$ were similar to those achieved $15 \mathrm{~min}$ after intravenous doses of 1-2.5 mg [8], indicating efficient absorption across the lung. Our assay measured parent morphine without detecting the glucuronide metabolites. The main purpose of this assay was to determine whether the nebulized drug was having a local action in the lung (i.e. if there had been a significant effect on the outcome variables in the absence of effective plasma levels). The measures of plasma concentrations indicated that the nebulized route of administration achieves plasma morphine concentrations that are capable of producing clinical effects, such as analgesia. It is evident that the lung is capable of delivering drugs via the pulmonary to the systemic circulation, thereby avoiding first pass hepatic metabolism. MAsood and THOmas [14] have shown that a $50 \mathrm{mg}$ nebulized dose results in a systemic bioavailability of morphine of $5.5 \%$. The plasma concentrations of morphine which we measured were comparable to those which have been reported previously [8].

Whilst there are experimental data in guinea-pigs suggesting that there are opiate receptors in the lung that are involved in control of breathing, whether afferent opiate receptors are present in human lung remains speculative. The present study, in which we could find no significant effect with inhaled morphine, does not provide any evidence for or against the existence of opiate receptors in the lung. The notion of whether the local application of opiates to the lung could relieve dyspnoea in patients with COPD depends on whether or not there are such afferent receptors present. If they do exist, they are not affected by doses of morphine that are sufficiently high to achieve effective plasma concentrations. However, other opiate analogues, such as morphine-6-glucuronide, may be useful. In a study of 18 patients with COPD using bicycle endurance testing, DAvis et al. [12] demonstrated that $4 \mathrm{mg}$ nebulized morphine-6-glucuronide increased exercise endurance, although there was no significant change in 6MWD. In addition, systemically administered morphine-6-glucuronide has been shown to cause less respiratory depression, sedation, nausea and vomiting than morphine [15].

The present study has shown that the lung is a route for rapid absorption of morphine. Thus, if there were an opiate that could reliably relieve dyspnoea via central nervous mechanisms then the lung remains a route for rapid drug delivery. The notion that patients with COPD could inhale an opiate derivative to obtain rapid relief of dyspnoea (possibly by systemic mechanisms) is worthy of further investigation. Although the present study shows that there is a lack of effect of high doses of nebulized morphine on exercise endurance and dyspnoea in COPD, there are other clinical situations in which nebulized morphine may have a therapeutic role, e.g. in cancer-associated dyspnoea and interstitial lung disease (ILD). There have been several reports concerning the effectiveness of nebulized morphine in relieving cancer-associated dyspnoea [16-18]. In a recent double-blind study using incremental cycle ergometer testing, HARRIS-EZE et al. [19] demonstrated that low dose (2.5 and $5 \mathrm{mg}$ ) nebulized morphine did not improve exercise performance or dyspnoea in patients with ILD. Higher doses, such as those used in the present study which are devoid of clinically significant side-effects are worthy of further study in the above conditions. On the other hand, more convenient (although probably slower acting) oral morphine in combination with other drugs, such as promethazine [20], may relieve dyspnoea without untoward side-effects, and such oral combinations may find more widespread application to relieve this distressing and common symptom.

\section{References}

1. Guyatt GH, Berman LB, Townsend M, Pugsley SO, Chambers LW. A measure of quality of life for clinical trials in chronic lung diseases. Thorax 1987; 42: 773778.

2. Woodcock AA, Gross ER, Gellert A, Shah S, Johnson M, Geddes DM. Effects of dihydrocodeine, alcohol and caffeine on breathlessness and exercise tolerance in patients with chronic obstructive lung disease and normal blood gases. N Engl J Med 1981; 305: 1611-1616.

3. Mitchell-Heggs P, Murphy K, Minty K. Diazepam in the treatment of dyspnoea in the "pink puffer" syndrome. Eur Respir J 1991; 4: 926-931.

4. Light RW, Munroe JR, Sato RI, Stansbury W, Fischer C, Brown SE. Effects of oral morphine on breathlessness and exercise tolerance in patients with chronic obstructive pulmonary disease. Am Rev Respir Dis 1989; 139: 126-133.

5. Fuller RW, Karlsson J-A, Choudry NB, Pride NB. Effect of inhaled and systemic opiates on responses to 
inhaled capsaicin in humans. J Appl Physiol 1988; 63: $1125-1130$.

6. Beauford W, Saylor TT, Stansbury DW, Avalos K, Light RW. Effects of nebulised morphine sulfate on exercise tolerance of the ventilatory limited COPD patient. Chest 1993; 104: 175-178.

7. Leung R, Hill P, Burdon J. Effect of inhaled morphine on the development of breathlessness during exercise in patients with chronic lung disease. Thorax 1996; 51: 596-600.

8. Masood AR, Reed JW, Thomas, SHL. Lack of effect of inhaled morphine on exercise-induced breathlessness in chronic obstructive pulmonary disease. Thorax 1995; 50: 629-634.

9. Buttland RJA, Pang J, Gross ER, Woodcock AA, Geddes EM. Two, six, and 12 minute walking tests in respiratory disease. Br Med J 1982; 284: 1607-1608.

10. Young IH, Daviskas E, Keena VA. Effects of low dose nebulised morphine on exercise endurance in patients with chronic lung disease. Thorax 1989; 44: 387390.

11. Humar A, Hodder R, Chauhan V, Calcutt L, Brown K. The effect of aerosolized morphine on exercise endurance and breathlessness in patients with advanced chronic lung disease. Am Rev Respir Dis 1995; 151: A548.

12. Davis C, Hodder C, Love S, Shah R, Slevin M, Wedzicha J. Effect of nebulised morphine and morphine-6-glucuronide on exercise endurance in patients with chro- nic obstructive pulmonary disease (Abstract). Thorax 1994; 49: 393P.

13. Borg GAV. Psychophysical bases of perceived exertion. Med Sci Sports Exerc 1982; 14: 377-381.

14. Masood AR, Thomas SHL. Systemic absorption of nebulized morphine compared with oral morphine in healthy subjects. Br J Clin Pharmacol 1996; 41: 250-252.

15. Thompson PI, Joel SP, John L, Wedzicha JA, Maclean M, Slevin ML. Respiratory depression following morphine and morphine-6-glucuronide in normal subjects. Br J Clin Pharmacol 1995; 40: 145-152.

16. Tooms A, McKenzie A, Grey H. Nebulised morphine. Lancet 1993; 342: 1123-1124.

17. Davis C. The role of nebulised drugs in palliating respiratory symptoms of malignant disease. Eur J Palliat Care 1995; 10: 9-15.

18. Farncombe M, Chater S. Case studies outlining use of nebulised morphine for patients with end-stage chronic lung and cardiac disease. J Pain Symptom Manage 1993; 8: 221-225.

19. Harris-Eze AO, Sridhar G, Clemens E, Zintel A, Gallagher CG, Marciniuk DD. Low-dose nebulised morphine does not improve exercise in interstitial lung disease. Am J Respir Crit Care Med 1995; 152: 1940-1945.

20. Light RW, Stansbury DW, Webster JS. Effect of $30 \mathrm{mg}$ of morphine alone or with promethazine or prochlorperazine on the exercise capacity of patients with COPD. Chest 1996; 109: 975-981. 